\title{
Electroencephalography for detection of vasospasm and delayed cerebral ischemia in aneurysmal subarachnoid hemorrhage: a retrospective analysis and systematic review
}

\author{
Lea Scherschinski, MD, Joshua S. Catapano, MD, Katherine Karahalios, MS, \\ Stefan W. Koester, MS, Dimitri Benner, BS, Ethan A. Winkler, MD, PhD, \\ Christopher S. Graffeo, MD, MS, Visish M. Srinivasan, MD, Ruchira M. Jha, MD, MSc, \\ Ashutosh P. Jadhav, MD, PhD, Andrew F. Ducruet, MD, Felipe C. Albuquerque, MD, and \\ Michael T. Lawton, MD
}

Department of Neurosurgery, Barrow Neurological Institute, St. Joseph’s Hospital and Medical Center, Phoenix, Arizona

OBJECTIVE Good functional outcomes after aneurysmal subarachnoid hemorrhage (aSAH) are often dependent on early detection and treatment of cerebral vasospasm (CVS) and delayed cerebral ischemia (DCI). There is growing evidence that continuous monitoring with cranial electroencephalography (cEEG) can predict CVS and DCl. Therefore, the authors sought to assess the value of continuous cEEG monitoring for the detection of CVS and DCl in aSAH.

METHODS The cerebrovascular database of a quaternary center was reviewed for patients with aSAH and cEEG monitoring between January 1, 2017, and July 31, 2019. Demographic data, cardiovascular risk factors, Glasgow Coma Scale score at admission, aneurysm characteristics, and outcomes were abstracted from the medical record. Patient data were retrospectively analyzed for DCl and angiographically assessed CVS. The sensitivity, specificity, positive predictive value (PPV), negative predictive value (NPV), and odds ratio for cEEG, transcranial Doppler ultrasonography (TCDS), CTA, and DSA in detecting $\mathrm{DCl}$ and angiographic CVS were calculated. A systematic literature review was conducted in accordance with PRISMA guidelines querying the PubMed, Cochrane Controlled Trials Register, Web of Science, and Embase databases.

RESULTS A total of 77 patients (mean age 60 years [SD 15 years]; female sex, $n=54$ ) were included in the study. Continuous CEEG monitoring detected DCl and angiographically assessed CVS with specificities of $82.9 \%(95 \% \mathrm{Cl}$ $66.4 \%-93.4 \%)$ and $94.4 \%(95 \% \mathrm{Cl} 72.7 \%-99.9 \%)$, respectively. The sensitivities were $11.1 \%(95 \% \mathrm{Cl} 3.1 \%-26.1 \%)$ for $\mathrm{DCl}(\mathrm{n}=71)$ and $18.8 \%(95 \% \mathrm{Cl} 7.2 \%-36.4 \%)$ for angiographically assessed CVS $(n=50)$. Furthermore, TCDS detected angiographically determined CVS with a sensitivity of $87.5 \%(95 \% \mathrm{Cl} 71.0 \%-96.5 \%)$ and specificity of $25.0 \%(95 \% \mathrm{Cl}$ $7.3 \%-52.4 \%$ ). In patients with DCI, TCDS detected vasospasm with a sensitivity of $85.7 \%(95 \% \mathrm{Cl} 69.7 \%-95.2 \%)$ and a specificity of $18.8 \%$ (95\% Cl 7.2\%-36.4\%). DSA detected vasospasm with a sensitivity of $73.9 \%(95 \% \mathrm{Cl} 51.6 \%-89.8 \%)$ and a specificity of $47.8 \%(95 \% \mathrm{Cl} 26.8 \%-69.4 \%)$.

CONCLUSIONS The study results suggest that continuous CEEG monitoring is highly specific in detecting $\mathrm{DCl}$ as well as angiographically assessed CVS. More prospective studies with predetermined thresholds and endpoints are needed to assess the predictive role of cEEG in aSAH.

https://thejns.org/doi/abs/10.3171/2021.12.FOCUS21656

KEYWORDS aneurysm; EEG; electroencephalography; delayed cerebral ischemia; SAH; subarachnoid hemorrhage; vasospasm

A NEURYSMAL subarachnoid hemorrhage (aSAH) causes significant morbidity and mortality. ${ }^{1,2}$ This debilitating condition affects as many as 10 individuals per 100,000 population per year. ${ }^{3}$ More than $10 \%$ of individuals who experience aSAH die before reach- ing the hospital, and an additional one-third of patients die within 24 hours of onset or remain in a poor clinical condition. ${ }^{3}$ Furthermore, approximately $50 \%$ of survivors remain cognitively disabled and unable to return to work. ${ }^{2}$

Cerebral vasospasm (CVS) and delayed cerebral is-

ABBREVIATIONS aSAH = aneurysmal subarachnoid hemorrhage; $c E E G$ = cranial electroencephalography; $C V S=$ cerebral vasospasm; $D C I=$ delayed cerebral ischemia; GCS = Glasgow Coma Scale; NPV = negative predictive value; PPV = positive predictive value; TCDS = transcranial Doppler ultrasonography.

SUBMITTED October 29, 2021. ACCEPTED December 22, 2021.

INCLUDE WHEN CITING DOI: 10.3171/2021.12.FOCUS21656. 
chemia (DCI) are significant factors associated with poor functional outcomes in aSAH. ${ }^{4} \mathrm{CVS}$ typically occurs between postbleed days 3 and 21, with a peak between days 6 and 8. ${ }^{5}$ Although CVS is known to be the main driving force in the pathogenesis of DCI, the current understanding of DCI is that it is an evolving multifactorial process comprising cerebral edema, blood-brain barrier disruption, sympathetic nervous system activation, autoregulatory failure, microthrombosis, spreading depolarizations, and inflammation starting as early as 24 hours postbleed and lasting as long as 3 weeks. ${ }^{6}$ Although the diagnosis of DCI relies on serial neurological examinations in adjunct to CT or MRI, the diagnosis of CVS can be established using transcranial Doppler ultrasonography (TCDS), CTA, or DSA.?

The early recognition and management of CVS and DCI are critical to prevent the debilitating sequelae of aSAH. ${ }^{8}$ However, the detection of these considerable pathological states remains challenging because of the restricted neurological examination possible in patients with poor-grade aSAH. ${ }^{9}$ Recently, there has been growing evidence that continuous monitoring with cranial electroencephalography (cEEG) may predict CVS and DCI. ${ }^{9}$ In this study, we assess the value of continuous cEEG monitoring for the detection of CVS and DCI in aSAH.

\section{Methods}

\section{Retrospective Analysis}

The Post-Barrow Ruptured Aneurysm Trial database was reviewed for patients with aSAH and cEEG from January 1,2017 , to July 31,2019 . Demographic data, cerebrovascular risk factors, Glasgow Coma Scale (GCS) score at admission, aneurysm characteristics, and outcomes were abstracted from the medical record and retrospectively analyzed. The cerebrovascular risk profile comprises hypertension, diabetes, smoking status, and cardiovascular disease.

The diagnostic modalities used to detect CVS were TCDS, CTA, DSA, clinical deterioration (defined as a new focal neurological deficit or a decrease in the level of consciousness), and continuous cEEG monitoring. The diagnosis of DCI was established in concordance with the universally valid definition, as either 1) a new focal neurological deficit, a decrease in the level of consciousness, and/or a decrease in the GCS score of at least 2 points for more than 1 hour in the absence of a relatable ischemic event; or 2) an infarct area emerging on CT, MRI, or confirmed on autopsy, after exclusion of procedure-related infarctions..$^{10}$ The clinical assessment of DCI was limited for a subset of patients in poor cognitive condition. The cEEG findings were considered positive if the final report of the attending epileptologist indicated vasospasm that occurred on the same day or within 24 hours after DCI diagnosis or angiographic indication of CVS.

The sensitivity, specificity, positive predictive value (PPV), negative predictive value (NPV), and odds ratio (OR) were calculated for each diagnostic modality in patients with DCI and patients with angiographically assessed CVS. The study was approved by the IRB at St. Joseph's Hospital and Medical Center (Phoenix, Arizona).
The need for written consent was waived because of the low risk to study subjects.

Data analysis was performed using R version 4.0.1 (The $\mathrm{R}$ Foundation). Data are represented as mean, standard deviation, and 25th and 75th percentile, when appropriate. Sensitivity, specificity, PPV, NPV, and OR are reported as percentages with $95 \%$ confidence intervals. The level of statistical significance was set at $\mathrm{p}<0.05$. Data were graphed with Prism version 9.0.2 (GraphPad Software).

\section{Systematic Literature Review}

In addition to analyzing our institutional experience, we conducted a systematic literature review in accordance with PRISMA guidelines. ${ }^{11}$ The PubMed, Cochrane Controlled Trials Register, Web of Science, and Embase databases were queried on September 31, 2021, using the terms "vasospasm, intracranial" or "delayed cerebral ischemia," in combination with "electroencephalography," "diagnosis," and "detection," either as Medical Subject Headings or as any other variation. No time period restrictions were applied. The resulting articles were screened by title and abstract and collected in an EndNote (Clarivate) library by a single reviewer. Data points that captured the prognostic and diagnostic values of cEEG, including sensitivity, specificity, PPV, and NPV measurements, were extracted. Clinical studies that allowed for data extraction related to the use of cEEG for the diagnosis and/or prognosis of vasospasm were included. We excluded all non-English-language articles and those not conducted on human subjects.

\section{Results}

\section{Patient and Aneurysm Characteristics}

A total of 77 patients met inclusion criteria during the study period. Following aSAH, 50 patients $(65 \%)$ were assessed for vasospasm angiographically and 71 patients (92\%) were assessed for DCI. The mean patient age was 60 years (SD 15 years), and 54 patients (70\%) were women. Hypertension, diabetes, and cardiovascular disease were present in $51(66 \%), 14(18 \%)$, and $25(32 \%)$ patients, respectively. Thirty-three patients $(43 \%)$ were active smokers. The mean GCS score at admission was 9.8 (SD 4.1). Aneurysms were diagnosed predominantly in the anterior circulation $(n=50,65 \%)$ and had a mean diameter of 6.1 $\mathrm{mm}$ (SD $3.8 \mathrm{~mm})$. At follow-up, 57 patients $(74 \%)$ had a modified Rankin Scale score greater than 2 (Table 1).,12

\section{Assessment of $\mathrm{DCl}$}

In patients with DCI $(\mathrm{n}=71)$, cEEG detected vasospasm with a sensitivity of $11.1 \%$ (95\% CI $3.1 \%-26.1 \%$ ) and specificity of $82.9 \%$ (95\% CI $66.4 \%-93.4 \%$ ). TCDS, CTA, and DSA detected vasospasm with much greater sensitivities of $85.7 \%$ (95\% CI 69.7\%-95.2\%), 70.6\% (95\% CI $52.5 \%-84.9 \%$ ), and $73.9 \%$ (95\% CI $51.6 \%-89.8 \%$ ), respectively. Compared with cEEG, TCDS, CTA, and DSA were significantly less specific, at $18.8 \%$ (95\% CI 7.2\%$36.4 \%$ ), $40.0 \%$ (95\% CI $21.1 \%-61.3 \%$ ), and $47.8 \%$ (95\% CI 26.8\%-69.4\%), respectively (Table 2 and Fig. 1).

In this cohort of patients with DCI, cEEG had a PPV of $40 \%$ (95\% CI 17.1\%-68.4\%) and an NPV of $47.5 \%$ (95\% CI $42.8 \%-52.3 \%)$. TCDS, DSA, and CTA had greater 
TABLE 1. Demographic and clinical characteristics of patients with aSAH and cEEG monitoring between January 1, 2017, and July 31, 2019

\begin{tabular}{lc}
\hline \multicolumn{1}{c}{ Characteristic } & Value $(\mathrm{n}=77)$ \\
\hline Mean age, yrs (SD) & $60(15)$ \\
\hline Female sex, $\mathrm{n}(\%)$ & $54(70)$ \\
\hline Vascular risk profile, $\mathrm{n}(\%)$ & $51(66)$ \\
\hline Hypertension & $14(18)$ \\
\hline Diabetes & $25(32)$ \\
\hline Cardiovascular disease & $33(43)$ \\
\hline Smoking & $18(23)$ \\
\hline GCS score at admission, $\mathrm{n}(\%)$ & $28(36)$ \\
\hline $3-6$ & $31(40)$ \\
\hline $7-11$ & $9.8(4.1)$ \\
\hline $12-15$ & 7,12 \\
\hline Mean GCS score at admission (SD) & $6.1(3.8)$ \\
\hline GCS score at admission, IQR & $50(65)$ \\
\hline Mean aneurysm size, mm (SD) & $57(74)$ \\
\hline Anterior circulation location, $\mathrm{n}(\%)$ &
\end{tabular}

$\mathrm{mRS}=$ modified Rankin Scale.

PPVs of $53.6 \%$ (95\% CI 48.2\%-58.9\%), 58.6\% (95\% CI $47.2 \%-69.2 \%)$, and $61.5 \%$ (95\% CI $52.1 \%-70.2 \%)$, respectively. In comparison with cEEG, TCDS and CTA both had similar NPVs of $54.6 \%$ (95\% CI 28.8\%-78.0\%) and $50.0 \%$ (95\% CI 33.0\%-67.0\%), respectively. DSA had the greatest NPV at $64.7 \%$ (95\% CI 44.9\%-80.5\%) (Table 2).

In clinically assessed patients with DCI, the OR was highest with DSA, with an OR of 2.6 (95\% CI 0.77-9.44), and lowest in cEEG, with an OR of 0.6 (95\% CI 0.142.33). CTA was associated with a higher OR of $1.6(95 \%$ CI 0.54-4.82) compared with TCDS (OR 1.38, 95\% CI 0.37-5.31) (Table 2 and Fig. 2). These findings were not statistically significant.

\section{Assessment of Vasospasm}

In patients with angiographic findings that indicated vasospasm, cEEG had a sensitivity of $18.8 \%$ (95\% CI 7.2\%$36.4 \%$ ) and a specificity of $94.4 \%$ (95\% CI 72.7\%-99.9\%). Comparatively, TCDS and CTA had 4.5-fold greater sensitivities of $87.5 \%$ (95\% CI $71.0 \%-69.5 \%)$ and $85.7 \%$ (95\% CI 67.3\%-96.0\%), respectively, followed by clinical examination, with a 3 -fold greater sensitivity of $58.6 \%$
(95\% CI 38.9\%-76.5\%). Compared with cEEG, CTA and clinical examination had lower specificities of $57.1 \%(95 \%$ CI $28.9 \%-82.3 \%$ ) and $64.7 \%$ (95\% CI 38.3\%-85.8\%), respectively. TCDS had the lowest specificity of $25.0 \%(95 \%$ CI 7.3\%-52.4\%) (Table 3 and Fig. 1).

In this cohort with angiographic findings positive for vasospasm, cEEG had the greatest PPV of $85.7 \%(95 \%$ CI $43.9 \%-97.9 \%$ ), followed by CTA with $80.0 \%$ (95\% CI $68.2 \%-88.2 \%$ ), clinical examination with $73.9 \%$ (95\% CI $58.2 \%-85.3 \%$ ), and TCDS with $70.0 \%$ (95\% CI $63.1 \%-$ $76.1 \%$ ). Additionally, cEEG had the lowest NPV of $39.5 \%$ (95\% CI 34.9\%-44.4\%), followed by clinical examination at $47.8 \%(95 \%$ CI $34.4 \%-61.6 \%)$, TCDS at $50.0 \%(95 \%$ CI $22.3 \%-77.7 \%$ ), and CTA at $66.7 \%$ (95\% CI $42.0 \%-84.7 \%$ ) (Table 3).

In angiographically assessed CVS, CTA had the highest reported OR of 8.0 (95\% CI 1.9-39.7), which was found to be statistically significant $(p=0.006)$. The OR for cEEG monitoring was next highest with an OR of 3.92 (95\% CI 0.6-77.6), followed by clinical assessment with an OR of 2.6 (95\% CI 0.77-9.44) and TCDS with an OR of 2.33 (95\% CI 0.48-11.4) (Table 3 and Fig. 2). These findings were not statistically significant.

\section{Results of the Systematic Literature Review}

The database search generated 720 articles. After excluding duplicates, articles not on human subjects, and non-English-language articles, as well as commentaries, editorials, and letters to the editor, the systematic literature review yielded a total of 53 articles. The full-text screening for appropriateness and availability for data extraction yielded 12 articles (Fig. 3). The articles were abstracted for key findings and conclusions to compare the findings of our institutional review with findings reported in the literature (Table 4). ${ }^{8,9,12-21}$

\section{Discussion}

Aneurysmal SAH is a devastating disease with a high morbidity and a 30-day mortality of $30 \%$ to $40 \%$, which is largely attributable to the occurrence of CVS and DCI. ${ }^{2}$ Although the current standard of care for recognition of neuronal damage depends on serial neurological examinations and vascular imaging studies, such as TCDS and CTA, recent studies have indicated that continuous $\mathrm{CEEG}$ monitoring may assist in the detection of CVS and DCI.$^{8,9}$, $12-15,18,20$ We conducted a retrospective analysis of the utility of continuous cEEG monitoring in a cohort of patients with poor-grade aSAH.

Continuous cEEG monitoring was highly specific for

TABLE 2. Detection of vasospasm in 71 patients with $\mathrm{DCI}$

\begin{tabular}{cccccccc}
\hline $\begin{array}{c}\text { Diagnostic } \\
\text { Method }\end{array}$ & $\begin{array}{c}\text { Sensitivity, } \\
\%(95 \% \mathrm{Cl})\end{array}$ & $\begin{array}{c}\text { Specificity, } \\
\%(95 \% \mathrm{Cl})\end{array}$ & $\begin{array}{c}\text { Youden } \\
\text { Index }\end{array}$ & $\begin{array}{c}\text { PPV, } \\
\%(95 \% \mathrm{Cl})\end{array}$ & $\begin{array}{c}\text { NPV, } \\
\%(95 \% \mathrm{Cl})\end{array}$ & $\begin{array}{c}\text { OR } \\
(95 \% \mathrm{Cl})\end{array}$ & $\begin{array}{c}\mathrm{p} \\
\text { Value }\end{array}$ \\
\hline CEEG & $11.1(3.1-26.1)$ & $82.9(66.4-93.4)$ & 0.53 & $40.0(17.1-68.4)$ & $47.5(42.8-52.3)$ & $0.60(0.14-2.33)$ & 0.5 \\
\hline TCDS & $85.7(69.7-95.2)$ & $18.8(7.2-36.4)$ & 0.52 & $53.6(48.2-58.9)$ & $54.6(28.8-78.0)$ & $1.38(0.37-5.31)$ & 0.6 \\
\hline CTA & $70.6(52.5-84.9)$ & $40.0(21.1-61.3)$ & 0.55 & $61.5(52.1-70.2)$ & $50.0(33.0-67.0)$ & $1.60(0.54-4.82)$ & 0.4 \\
\hline DSA & $73.9(51.6-89.8)$ & $47.8(26.8-69.4)$ & 0.61 & $58.6(47.2-69.2)$ & $64.7(44.9-80.5)$ & $2.60(0.77-9.44)$ & 0.13 \\
\hline
\end{tabular}


A
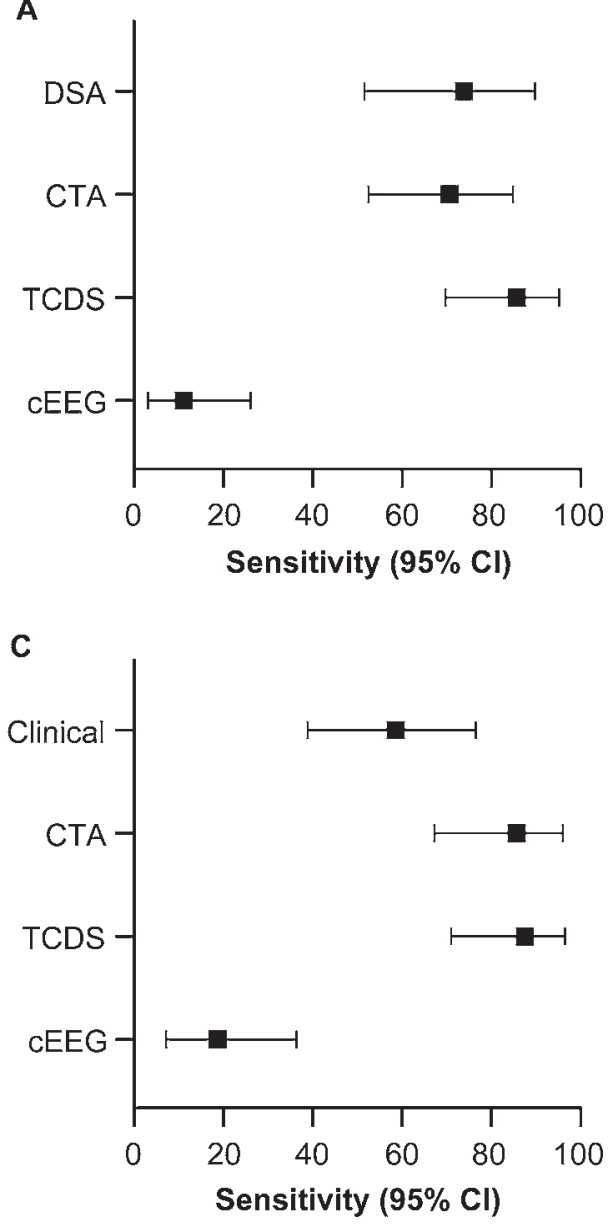

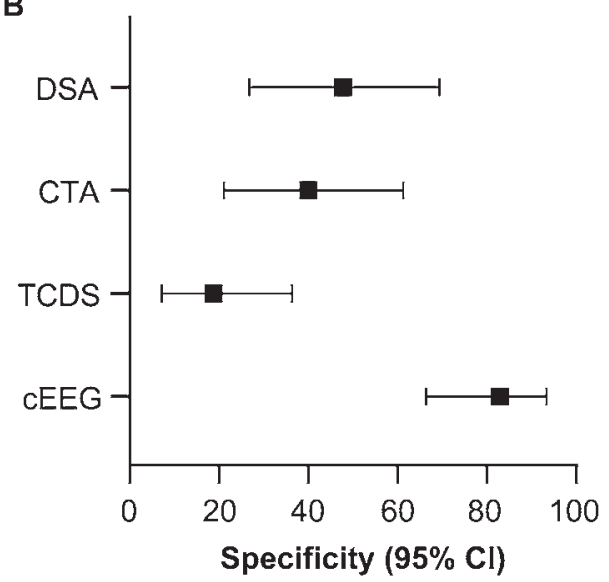

D

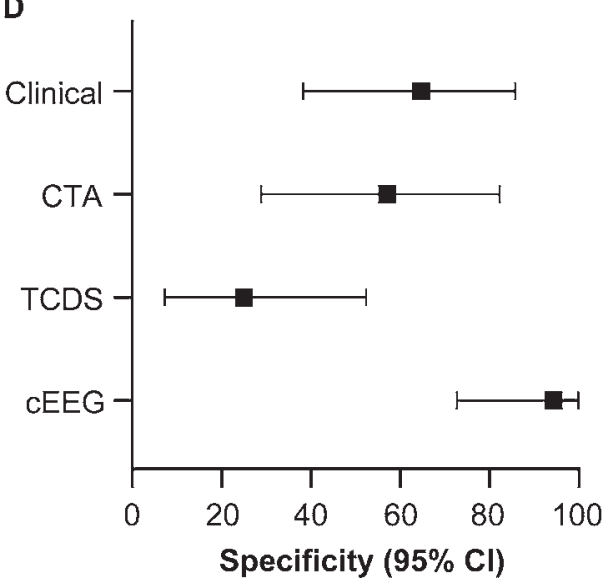

FIG. 1. Sensitivity and specificity of diagnostic methods in patients with clinically assessed DCl and angiographically assessed CVS. A: Forest plot showing the sensitivities of DSA, CTA, TCDS, and CEEG in clinically assessed DCI. B: Forest plot showing the specificities of DSA, CTA, TCDS, and CEEG in clinically assessed DCI. C: Forest plot showing the sensitivities of clinical assessment, CTA, TCDS, and cEEG in angiographically assessed vasospasm. D: Forest plot showing the specificities of clinical assessment, CTA, TCDS, and CEEG in angiographically assessed vasospasm.
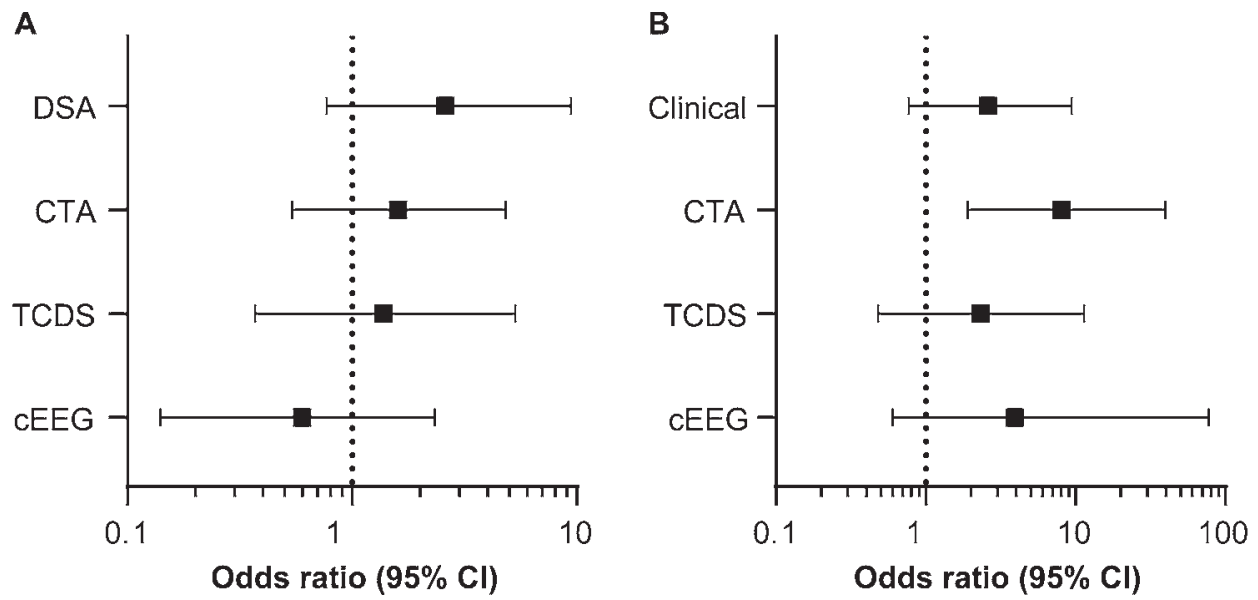

FIG. 2. OR of diagnostic methods in patients with clinically assessed DCl and angiographically assessed CVS. A: Forest plot showing the OR and $95 \% \mathrm{Cl}$ of DSA, CTA, TCDS, and CEEG in clinically assessed DCl. B: Forest plot showing the OR and $95 \%$ $\mathrm{Cl}$ of clinical assessment, CTA, TCDS, and cEEG in angiographically assessed vasospasm. 
TABLE 3. Detection of vasospasm in 50 patients with angiographically assessed CVS

\begin{tabular}{llcccccc}
\hline $\begin{array}{c}\text { Diagnostic } \\
\text { Method }\end{array}$ & $\begin{array}{c}\text { Sensitivity, } \\
\%(95 \% \mathrm{Cl})\end{array}$ & $\begin{array}{c}\text { Specificity, } \\
\%(95 \% \mathrm{Cl})\end{array}$ & $\begin{array}{c}\text { Youden } \\
\text { Index }\end{array}$ & $\begin{array}{c}\text { PPV, } \\
\%(95 \% \mathrm{Cl})\end{array}$ & $\begin{array}{c}\text { NPV, } \\
\%(95 \% \mathrm{Cl})\end{array}$ & $\begin{array}{c}\text { OR } \\
(95 \% \mathrm{Cl})\end{array}$ & $\begin{array}{c}\mathrm{p} \\
\text { Value }\end{array}$ \\
\hline CEEG & $18.8(7.2-36.4)$ & $94.4(72.7-99.9)$ & 0.57 & $85.7(43.9-97.9)$ & $39.5(34.9-44.4)$ & $3.92(0.60-77.6)$ & 0.2 \\
\hline TCDS & $87.5(71.0-96.5)$ & $25.0(7.3-52.4)$ & 0.56 & $70.0(63.1-76.1)$ & $50.0(22.3-77.7)$ & $2.33(0.48-11.4)$ & 0.3 \\
\hline CTA & $85.7(67.3-96.0)$ & $57.1(28.9-82.3)$ & 0.71 & $80.0(68.2-88.2)$ & $66.7(42.0-84.7)$ & $8.00(1.90-39.7)$ & 0.006 \\
\hline Clinical & $58.6(38.9-76.5)$ & $64.7(38.3-85.8)$ & 0.62 & $73.9(58.2-85.3)$ & $47.8(34.4-61.6)$ & $2.60(0.77-9.44)$ & 0.13 \\
\hline
\end{tabular}

angiographically assessed CVS and DCI, with specificities ranging from $80 \%$ to $95 \%$. However, we also found cEEG monitoring to be associated with sensitivities as low as $11 \%$ for DCI and 19\% for angiographically assessed CVS. In 2004, Claassen et al. reported a similar specificity of $84 \%$ among patients, with a single cEEG recording showing greater than $50 \%$ decrease in the alpha-delta ratio from baseline ${ }^{15}$ However, the sensitivities that they reported for DCI detection were significantly higher than our findings, at $89 \%$ to $100 \% .{ }^{15}$ Likewise, in 2016 , Rots et al. observed a high specificity of $83.3 \%$ in a cohort of 8 patients with confirmed DCI. ${ }^{12}$ They also found cEEG monitoring to be $100 \%$ sensitive for detection of DCI, using a greater than $38 \%$ decrease in either the alpha-delta ratio or the alpha variability as the threshold..$^{12}$ In 2018 , a study by Balança et al. verified the use of continuous cEEG monitoring as a feasible predictor to detect DCI, based on $100 \%$ sensitivity and $88.9 \%$ specificity observed with a regional $30 \%$ alphatheta/delta ratio decrease lasting more than 3.7 hours. ${ }^{8}$ In a prospective study, Rosenthal et al. concluded that continuous cEEG monitoring accurately predicted DCI. ${ }^{20}$ Their claims were substantiated by a $91 \%$ sensitivity and an $83 \%$

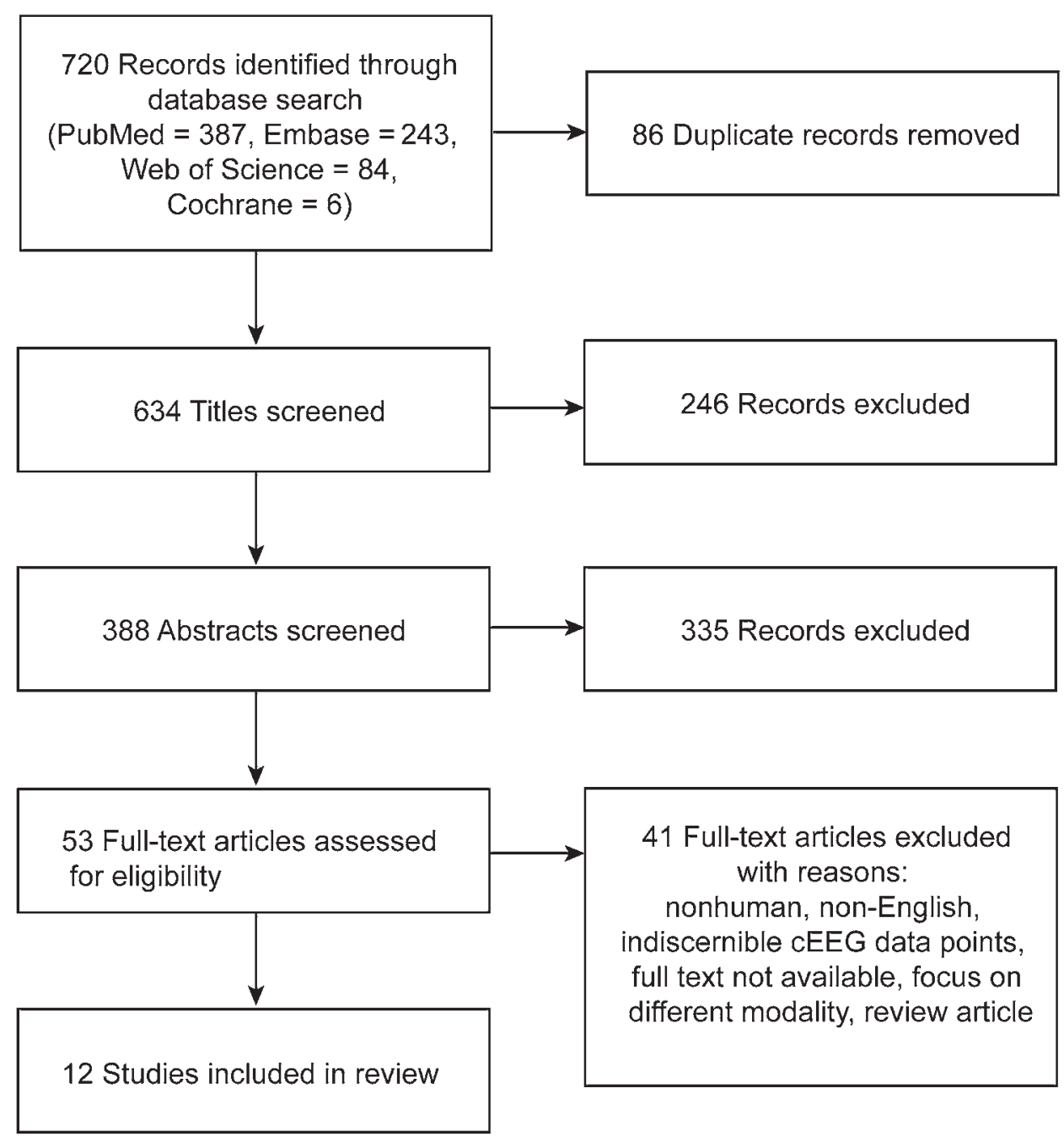

FIG. 3. PRISMA flowchart outlining the systematic literature review. 
TABLE 4. Systematic literature review on the utility of EEG to detect vasospasm and DCI in aSAH

\begin{tabular}{ll}
\hline \multicolumn{1}{c}{$\begin{array}{c}\text { Authors \& } \\
\text { Year }\end{array}$} & \multicolumn{1}{c}{ Title } \\
\hline $\begin{array}{l}\text { Rivierez et al., } \\
1991^{13}\end{array}$ & "Value of electroencephalogram in predic- \\
& $\begin{array}{l}\text { tion and diagnosis of vasospasm after } \\
\text { intracranial aneurysm rupture" }\end{array}$
\end{tabular}

No. of

Pts

151 Early prognostic value of EEG on 1st postbleed day: among $46 \mathrm{pts} w /$ normal EEG findings, 33 (72\%) did not present w/ further electrical ischemic features or delayed angiographic vasospasm; among 78 pts w/ aberrant EEG findings, 76 (97\%) exhibited EEG signs of ischemia \& angiographic vasospasm several days later. Late diagnostic value of EEG on postbleed day 5: among 107 pts w/ aberrant EEG findings, 103 (96\%) were assessed for vasospasm angiographically.

Vespa et al., "Early detection of vasospasm after acute $1997^{14} \quad$ subarachnoid hemorrhage using continuous EEG ICU monitoring"

32 In 19/19 pts w/ angiographically assessed vasospasm, the relative alpha activity was low but improved w/ resolution of vasospasm. In 10/19 pts, the EEG abnormalities preceded the diagnosis of vasospasm by a mean of 2.9 days (SD 1.73 days). PPV, 76\%; NPV, 100\%. 12 /19 pts exhibited clinical signs of vasospasm at the time of EEG alterations. Decreased relative alpha variability provides early detection of vasospasm in pts before clear clinical symptoms \& signs occur.

\begin{tabular}{|c|c|}
\hline $\begin{array}{l}\text { Claassen et } \\
\text { al., } 2004^{15}\end{array}$ & $\begin{array}{l}\text { "Quantitative continuous EEG for detecting } \\
\text { delayed cerebral ischemia in patients } \\
\text { with poor-grade subarachnoid hemor- } \\
\text { rhage" }\end{array}$ \\
\hline $\begin{array}{l}\text { Stuart et al., } \\
2010^{16}\end{array}$ & $\begin{array}{l}\text { "Intracortical EEG for the detection of } \\
\text { vasospasm in patients with poor-grade } \\
\text { subarachnoid hemorrhage" }\end{array}$ \\
\hline
\end{tabular}

34 EEG had a $100 \%$ sensitivity \& $76 \%$ specificity when 6 consecutive recordings had a $>10 \%$ decrease in alpha-delta ratio from baseline. EEG had a $89 \%$ sensitivity \& $84 \%$ specificity when any single measurement had a $>50 \%$ decrease in alpha-delta ratio from baseline.

5 Intracortical EEG showed a decrease in alpha-delta ratio from baseline ( $>25 \%$ for $\geq 4 \mathrm{hrs}$ ) in all $3 \mathrm{pts} w /$ angiographically confirmed vasospasm \& not in the 2 pts w/o vasospasm. Early predictive value of intracortcial EEG: the decline occurred 1-3 days before angiographic confirmation. Intracortical continuous EEG may be superior to scalp EEG in detecting vasospasm.

Rathakrishnan "Using continuous electroencephalography et al., 201117 in the management of delayed cerebral ischemia following subarachnoid hemorrhage"

13 Sensitivity of predicting clinical deterioration w/ EEG improved from $40 \%$ to $67 \%$ \& of predicting clinical improvement $w /$ EEG improved from $8 \%$ to $50 \%$. Predictive value of EEG in clinical deterioration: $67 \%$ sensitivity \& $73 \%$ specificity. In 3/12 pts, EEG was predictive $>24$ hrs before clinical change. Tracking the daily mean alpha power accurately identified $\mathrm{DCl}$ recurrence \& poor responders to first-line therapy at preclinical stages. EEG is a useful noninvasive tool to supplement routine clinical parameters in the prediction of $\mathrm{DCl}$. It can dynamically monitor the response to treatment \& might aid preclinical management decisions.

\begin{tabular}{ll}
\hline Gollwitzer et & "Early prediction of delayed cerebral ische- \\
al., $2015^{9}$ & mia in subarachnoid hemorrhage based \\
& on quantitative EEG: a prospective study \\
& in adults"
\end{tabular}

12 EEG had $89 \%$ sensitivity \& $77 \%$ specificity w/ decrease of $>40 \%$ in power persisting $>5 \mathrm{hrs}$ in the alpha band \& $>6 \mathrm{hrs}$ in the theta band. EEG changes preceded detection of vasospasm \& $\mathrm{DCl}$ in standard procedures by 2.3 days. Focal reduction in alpha power may represent a valid, observerindependent, noninvasive, \& continuous marker for vasospasm \& $\mathrm{DCl}$ in pts w/ SAH.

Rots et al., "Continuous EEG monitoring for early
$2016^{12}$ $\begin{aligned} & \text { detection of delayed cerebral ischemia in } \\ & \text { subarachnoid hemorrhage: a pilot study" }\end{aligned}$

20 Early detection of $\mathrm{DCl}$ : all 8 pts $\mathrm{w} / \mathrm{DCl}$ showed a decrease of $>38 \%$ of either alpha-delta ratio or alpha variability ( $100 \%$ sensitivity, $83.3 \%$ specificity). In $5 / 8$ pts, the $\mathrm{DCl}$-compatible EEG changes were found before clinical $\mathrm{DCl}$ diagnosis. Continuous EEG detected $\mathrm{DCl} 7 \mathrm{hrs}$ earlier than clinical deterioration \& 44 hrs earlier than $C T$.

\begin{tabular}{lc}
\hline $\begin{array}{l}\text { Kim et al., } \\
2017^{18}\end{array}$ & $\begin{array}{l}\text { "Epileptiform abnormalities predict delayed } \\
\text { cerebral ischemia in subarachnoid } \\
\text { hemorrhage" }\end{array}$ \\
\hline $\begin{array}{l}\text { Wickering et } \\
\text { al., 201619 }\end{array}$ & $\begin{array}{l}\text { Automation of classical QEEG trending } \\
\text { methods for early detection of delayed } \\
\text { cerebral ischemia: more work to do" }\end{array}$
\end{tabular}

124 Presence of IICAs was associated w/ higher risk of $\mathrm{DCl}$, especially if they emerged late in the acute period after SAH. Quantification of IICA features may assist in the development of an algorithm to predict $\mathrm{DCl}$ risk.

85 The highest sensitivity \& specificity of alpha-delta ratio decrease detected by the automated EEG-based early DCI-detection system were $95 \%$ \& $34 \%$, respectively. The mean time btwn the 1st change in EEG activity \& the clinical DCI was 3.9 days. Improved methods to detect decreases in alpha-delta ratio \& relative alpha variability are needed before an automated EEG-based early DCl-detection system is ready for clinical use. 
» CONTINUED FROM PAGE 6

TABLE 4. Systematic literature review on the utility of EEG to detect vasospasm and DCI in aSAH

\begin{tabular}{|c|c|c|c|}
\hline $\begin{array}{c}\text { Authors \& } \\
\text { Year }\end{array}$ & Title & $\begin{array}{l}\text { No. of } \\
\text { Pts }\end{array}$ & Key Findings \& Conclusions \\
\hline $\begin{array}{l}\text { Balança et al., } \\
2018^{8}\end{array}$ & $\begin{array}{l}\text { "Diagnostic accuracy of quantitative EEG } \\
\text { to detect delayed cerebral ischemia after } \\
\text { subarachnoid hemorrhage: a preliminary } \\
\text { study" }\end{array}$ & 15 & $\begin{array}{l}\text { A regional } 30 \% \text { alpha-theta/delta ratio decrease outlasting } 3.7 \mathrm{hrs} \text { reached } \\
100 \% \text { sensitivity \& } 88.9 \% \text { specificity to detect } \mathrm{DCl} \text {. A regional } 50 \% \text { alpha- } \\
\text { theta/delta ratio decrease outlasting } 3.7 \mathrm{hrs} \text { reached } 89.9 \% \text { sensitivity \& } \\
83.3 \% \text { specificity to detect } \mathrm{DCl} \text {. Prolonged alpha-theta/delta ratio decrease } \\
\text { starting in } 1 \text { territory seems to be a good biomarker of } \mathrm{DCl} \text {. }\end{array}$ \\
\hline $\begin{array}{l}\text { Rosenthal et } \\
\text { al., } 2018^{20}\end{array}$ & $\begin{array}{l}\text { "Continuous electroencephalography } \\
\text { predicts delayed cerebral ischemia after } \\
\text { subarachnoid hemorrhage: a prospective } \\
\text { study of diagnostic accuracy" }\end{array}$ & 103 & $\begin{array}{l}\text { EEG alarms occurred in } 96.2 \% \text { of pts w/ \& } 19.6 \% \text { of pts w/o subsequent DCI } \\
\text { (1.9-day median latency). Predictive value of EEG in DCl: sensitivity, } 96.2 \% \text {; } \\
\text { specificity, } 80.4 \% \text {; PPV, } 83.3 \% ; \& \text { NPV, } 95.4 \% \text {. Among alarm subtypes, late- } \\
\text { onset epileptiform abnormalities had the highest predictive value. Prespeci- } \\
\text { fied EEG findings predicted DCl among pts w/ low ( } 91 \% \text { sensitivity, } 83 \% \\
\text { specificity) \& high ( } 95 \% \text { sensitivity, } 77 \% \text { specificity) baseline risk. Continu- } \\
\text { ous EEG accurately predicts DCl after SAH. }\end{array}$ \\
\hline $\begin{array}{l}\text { Spalletti et al., } \\
2019^{21}\end{array}$ & $\begin{array}{l}\text { "Amplitude instability of somatosensory } \\
\text { evoked potentials as an indicator of } \\
\text { delayed cerebral ischemia in a case of } \\
\text { subarachnoid hemorrhage" }\end{array}$ & 1 & $\begin{array}{l}\text { A 55-yr-old man w/ aSAH was monitored w/ continuous EEG-SSEPs. A } \\
\text { prolonged phase of SSEP amplitude instability correlated w/ a phase of } \\
\text { ischemic penumbra, as demonstrated by CT perfusion. EEG monitor- } \\
\text { ing remained relatively uninformative due to neurosedation. Continuous } \\
\text { EEG-SSEP monitoring could be included in the multimodal assessment of } \\
\text { vasospasm from TCDS \& DSA. }\end{array}$ \\
\hline
\end{tabular}

IICA = ictal-interictal continuum abnormality; pts = patients; SSEP = somatosensory evoked potential .

specificity in patients with a low baseline risk of DCI, as well as a $95 \%$ sensitivity and a $77 \%$ specificity in patients with an elevated baseline risk of DCI. ${ }^{20}$

All the above studies suggest a high diagnostic accuracy of cEEG monitoring in detecting CVS and DCI. Although our findings affirm the high specificity of cEEG reported in the literature, we found much lower sensitivity than other studies. The lower sensitivity of cEEG monitoring in DCI may be attributable to institutional differences or biases among observers. For instance, although the clinical aspect of the standard DCI definition is provided by a new focal neurological deficit, a decrease in the level of consciousness, and/or a decrease in the GCS score of at least 2 points for more than 1 hour in the absence of a relatable ischemic event, institutions may have altered these guidelines in favor of better patient care and better outcomes. . $^{1018,19,22}$ This change may be associated with a high rate of false-positive DCI diagnoses among patients with poor clinical condition.

Although other studies have assessed the diagnostic capacity of cEEG monitoring for detection of CVS, ${ }^{13,14} \mathrm{cEEG}$ actually measures aberrant neuronal activity, which translates into the assessment of DCI. In contrast, DSA, TCDS, and CTA evaluate vasospasm on the basis of changes in vessel diameter and cerebral flow velocities. The paradigm stating that DCI results solely from vasospasm has long been abandoned, and recent studies have provided reason to believe that the pathogenesis of DCI is an evolving multifactorial process, implicating the role of microvasculature, coagulation and fibrinolysis, cortical spreading depressions, and the immune system. ${ }^{4,6}$ Therefore, although continuous cEEG monitoring does not directly measure CVS, it indirectly measures the processes that induce and maintain brain injury in DCI.
DSA is considered the diagnostic gold standard for the early recognition and treatment of CVS. ${ }^{23-25}$ Although DSA is associated with some risk because it is an invasive procedure, recent advances have made these procedures safer. ${ }^{26,27}$ Furthermore, DSA offers major advantages that include its accuracy and the ability to immediately administer vasodilatory agents intraarterially. ${ }^{23-25}$ Arias et al. assessed a sensitivity of $80 \%$ and a specificity of $71 \%$ for DSA in detecting CVS among patients who were transiently symptomatic or had poor neurological examination findings. ${ }^{25}$ We found DSA to be less sensitive (73.9\%) and less specific $(47.7 \%)$ in patients with clinical deterioration. The decreased sensitivity and specificity of DSA in these patients may be attributed to the subset of patients in our cohort with significantly poor neurological examination findings, which can make the clinical interpretation of CVS challenging.

We also evaluated the capacity of TCDS to detect angiographically assessed CVS. TCDS detected angiographically determined CVS with an $87.5 \%$ sensitivity, $25.0 \%$ specificity, PPV of $70 \%$, and NPV of $50 \%$. These sensitivity findings are in accordance with previously reported values of $84 \%$ to $85 \% .^{24,28-31}$ In a prospective study by Mascia et al., TCDS was found to be $100 \%$ sensitive and $75 \%$ specific for angiographic CVS, with a PPV of $72 \%$ and NPV of $100 \% .^{31}$ Likewise, Sloan et al. found TCDS to be $100 \%$ sensitive for angiographic CVS; however, the authors reported a lower specificity of $58.6 \% .^{30}$ The lower specificities of TCDS in angiographic CVS may be explained by the limitations associated with TCDS, which include interobserver variability and restricted access to the entire cerebral vasculature, resulting in diagnostic variation. ${ }^{24}$ Nonetheless, the advantages of TCDS include that it is noninvasive, broadly available, low cost, and asso- 
ciated with a low risk to patients, as well as having higher sensitivity and specificity than DSA..$^{24,29}$

\section{Limitations}

Potential limitations of our study include its retrospective nature and the small study population. In addition, the randomization of the study population was lost because continuous cEEG monitoring is reserved for patients with high-grade SAH who have particularly poor neurological examination findings. Subsequently, the large proportion of patients with poor clinical performance may have affected the observer's clinical assessment of DCI. In general, DCI is a challenging condition to diagnose, especially retrospectively. Despite the attempt to standardize the diagnosis of DCI with the help of uniform definitions, it remains a subjective diagnosis with potentially high interobserver variability. Furthermore, the guidelines for diagnosing vasospasm and DCI with use of different diagnostic modalities may vary among institutions, possibly creating a bias when the findings of individual studies are compared. This limitation becomes evident when comparing the studies identified by our literature review, as each has reported different thresholds and endpoints (Table 4). Finally, although cEEG findings were considered positive only when occurring on the same day or within 24 hours after DCI diagnosis or changes on DSA, this study has limited value in assessing the early predictive value of cEEG monitoring for CVS or DCI screening.

\section{Conclusions}

Altogether, continuous cEEG monitoring offers noninvasive, continuous real-time measurements of neuronal activity, which can be correlated with the development of DCI. ${ }^{8}$ Because one-fifth of patients with DCI remain asymptomatic, cEEG may be considered a feasible adjunct to the current standard of care techniques, such as TCDS and DSA. ${ }^{22}$ We found that continuous cEEG monitoring was highly specific for CVS and DCI for patients with aSAH. However, cEEG was found to have a low sensitivity, and it requires adjunct modalities for screening. Further prospective studies with predetermined thresholds and endpoints are needed to assess the role of continuous cEEG monitoring in detecting CVS and DCI after aSAH.

\section{Acknowledgments}

We thank the staff of Neuroscience Publications at Barrow Neurological Institute for assistance with manuscript preparation.

\section{References}

1. Ciurea AV, Palade C, Voinescu D, Nica DA. Subarachnoid hemorrhage and cerebral vasospasm-literature review. $J$ Med Life. 2013;6(2):120-125.

2. Kreiter KT, Copeland D, Bernardini GL, et al. Predictors of cognitive dysfunction after subarachnoid hemorrhage. Stroke. 2002;33(1):200-208.

3. Hijdra A, Braakman R, van Gijn J, Vermeulen M, van Crevel H. Aneurysmal subarachnoid hemorrhage. Complications and outcome in a hospital population. Stroke. 1987;18(6): 1061-1067.

4. Geraghty JR, Testai FD. Delayed cerebral ischemia after subarachnoid hemorrhage: beyond vasospasm and towards a multifactorial pathophysiology. Curr Atheroscler Rep. 2017; 19(12):50.

5. Wilkins RH. Cerebral vasospasm. Crit Rev Neurobiol. 1990; 6(1):51-77.

6. Dodd WS, Laurent D, Dumont AS, et al. Pathophysiology of delayed cerebral ischemia after subarachnoid hemorrhage: a review. J Am Heart Assoc. 2021;10(15):e021845.

7. Li K, Barras CD, Chandra RV, et al. A review of the management of cerebral vasospasm after aneurysmal subarachnoid hemorrhage. World Neurosurg. 2019;126:513-527.

8. Balança B, Dailler F, Boulogne S, et al. Diagnostic accuracy of quantitative EEG to detect delayed cerebral ischemia after subarachnoid hemorrhage: a preliminary study. Clin Neurophysiol. 2018;129(9):1926-1936.

9. Gollwitzer S, Groemer T, Rampp S, et al. Early prediction of delayed cerebral ischemia in subarachnoid hemorrhage based on quantitative EEG: a prospective study in adults. Clin Neurophysiol. 2015;126(8):1514-1523.

10. Vergouwen MD, Vermeulen M, van Gijn J, et al. Definition of delayed cerebral ischemia after aneurysmal subarachnoid hemorrhage as an outcome event in clinical trials and observational studies: proposal of a multidisciplinary research group. Stroke. 2010;41(10):2391-2395.

11. Moher D, Liberati A, Tetzlaff J, Altman DG. Preferred reporting items for systematic reviews and meta-analyses: the PRISMA statement. Ann Intern Med. 2009;151(4):264-269, W64.

12. Rots ML, van Putten MJ, Hoedemaekers CW, Horn J. Continuous EEG monitoring for early detection of delayed cerebral ischemia in subarachnoid hemorrhage: a pilot study. Neurocrit Care. 2016;24(2):207-216.

13. Rivierez M, Landau-Ferey J, Grob R, Grosskopf D, Philippon $\mathrm{J}$. Value of electroencephalogram in prediction and diagnosis of vasospasm after intracranial aneurysm rupture. Acta Neurochir (Wien). 1991;110(1-2):17-23.

14. Vespa PM, Nuwer MR, Juhász C, et al. Early detection of vasospasm after acute subarachnoid hemorrhage using continuous EEG ICU monitoring. Electroencephalogr Clin Neurophysiol. 1997;103(6):607-615.

15. Claassen J, Hirsch LJ, Kreiter KT, et al. Quantitative continuous EEG for detecting delayed cerebral ischemia in patients with poor-grade subarachnoid hemorrhage. Clin Neurophysiol. 2004;115(12):2699-2710.

16. Stuart RM, Waziri A, Weintraub D, et al. Intracortical EEG for the detection of vasospasm in patients with poor-grade subarachnoid hemorrhage. Neurocrit Care. 2010;13(3):355358.

17. Rathakrishnan R, Gotman J, Dubeau F, Angle M. Using continuous electroencephalography in the management of delayed cerebral ischemia following subarachnoid hemorrhage. Neurocrit Care. 2011;14(2):152-161.

18. Kim JA, Rosenthal ES, Biswal S, et al. Epileptiform abnormalities predict delayed cerebral ischemia in subarachnoid hemorrhage. Clin Neurophysiol. 2017;128(6):1091-1099.

19. Wickering E, Gaspard N, Zafar S, et al. Automation of classical QEEG trending methods for early detection of delayed cerebral ischemia: more work to do. J Clin Neurophysiol. 2016;33(3):227-234.

20. Rosenthal ES, Biswal S, Zafar SF, et al. Continuous electroencephalography predicts delayed cerebral ischemia after subarachnoid hemorrhage: a prospective study of diagnostic accuracy. Ann Neurol. 2018;83(5):958-969.

21. Spalletti M, Orzalesi V, Carrai R, et al. Amplitude instability of somatosensory evoked potentials as an indicator of delayed cerebral ischemia in a case of subarachnoid hemorrhage. Clin EEG Neurosci. 2019;50(3):205-209.

22. Schmidt JM, Wartenberg KE, Fernandez A, et al. Frequency and clinical impact of asymptomatic cerebral infarction due 
to vasospasm after subarachnoid hemorrhage. J Neurosurg. 2008;109(6):1052-1059.

23. Kim JH, Yi JH, Chang CH, Jung YJ. Evaluation of the accuracy in maximum intensity projection images of cerebral Computed tomographic angiography for the diagnosis of cerebral vasospasm following subarachnoid hemorrhage, in comparison to digital subtraction angiography. $J$ Cerebrovasc Endovasc Neurosurg. 2018;20(1):5-13.

24. Anderson GB, Ashforth R, Steinke DE, Findlay JM. CT angiography for the detection of cerebral vasospasm in patients with acute subarachnoid hemorrhage. AJNR Am J Neuroradiol. 2000;21(6):1011-1015.

25. Arias EJ, Vajapey S, Reynolds MR, et al. Utility of screening for cerebral vasospasm using digital subtraction angiography. Stroke. 2015;46(11):3137-3141.

26. Catapano JS, Ducruet AF, Nguyen CL, et al. Propensityadjusted comparative analysis of radial versus femoral access for neurointerventional treatments. Neurosurgery. 2021;88(6): E505-E509.

27. Catapano JS, Fredrickson VL, Fujii T, et al. Complications of femoral versus radial access in neuroendovascular procedures with propensity adjustment. J Neurointerv Surg. 2020; 12(6):611-615.

28. Kumar G, Shahripour RB, Harrigan MR. Vasospasm on transcranial Doppler is predictive of delayed cerebral ischemia in aneurysmal subarachnoid hemorrhage: a systematic review and meta-analysis. J Neurosurg. 2016;124(5):12571264.

29. Lindegaard KF, Nornes H, Bakke SJ, Sorteberg W, Nakstad P. Cerebral vasospasm diagnosis by means of angiography and blood velocity measurements. Acta Neurochir (Wien). 1989;100(1-2):12-24.

30. Sloan MA, Haley EC Jr, Kassell NF, et al. Sensitivity and specificity of transcranial Doppler ultrasonography in the diagnosis of vasospasm following subarachnoid hemorrhage. Neurology. 1989;39(11):1514-1518.
31. Mascia L, Fedorko L, terBrugge K, et al. The accuracy of transcranial Doppler to detect vasospasm in patients with aneurysmal subarachnoid hemorrhage. Intensive Care Med. 2003;29(7):1088-1094.

\section{Disclosures}

Dr. Jha: consultant for Biogen. Dr. Ducruet: consultant for Penumbra, Cerenovus, Medtronic, Stryker, Koswire, and Oculus.

\section{Author Contributions}

Conception and design: Lawton, Scherschinski, Catapano, Winkler, Graffeo, Srinivasan, Jha, Jadhav, Ducruet, Albuquerque. Acquisition of data: Scherschinski, Karahalios, Benner. Analysis and interpretation of data: Scherschinski, Catapano, Karahalios, Koester, Benner. Drafting the article: Scherschinski. Critically revising the article: Lawton, Scherschinski, Catapano, Karahalios, Winkler, Graffeo, Srinivasan, Jha, Jadhav, Ducruet, Albuquerque. Reviewed submitted version of manuscript: all authors. Statistical analysis: Catapano, Koester. Study supervision: Lawton, Catapano.

\section{Supplemental Information \\ Videos \\ Video Abstract. https://vimeo.com/675878437.}

\section{Correspondence}

Michael T. Lawton: c/o Neuroscience Publications, Barrow Neurological Institute, St. Joseph's Hospital and Medical Center, Phoenix,AZ.neuropub@barrowneuro.org. 